\title{
Synthesis of poly(ether sulfone)s by self-polycondensation of AB-type monomers
}

\author{
Kazuya Matsumoto, Hitoshi Komuro, Takuya Kai and Mitsutoshi Jikei
}

Self-polycondensation of AB-type monomers is an advantageous route to produce high-molecular-weight polymers without considerable adjustment in the mole ratio of the functionalities. Furthermore, the resulting polymers incorporate two different functional groups at the chain ends that enable the preparation of $A B$ - and ABC-type block copolymers. In this study, poly(ether sulfone)s (PESs) were prepared via self-polycondensation of four AB-type monomers. The reactivity of the AB-type monomers was systematically investigated through model reactions and nuclear magnetic resonance measurements, which suggested that the novel AB-type monomers, 4-chloro-4'-(hydroxyphenyloxy)diphenylsulfone (monomer C) and 4-fluoro-4'-(hydroxyphenyloxy)diphenylsulfone (monomer $\mathrm{D}$ ), are highly susceptible to nucleophilic aromatic substitution $\left(\mathrm{S}_{\mathrm{N}} \mathrm{Ar}\right)$ reactions. High-molecular-weight PESs $\left(M_{\mathrm{w}}>110000\right)$ were obtained via the self-polycondensation of monomers $\mathrm{C}$ and $\mathrm{D}$. The resulting PESs exhibited excellent thermal properties comparable with PESs prepared from $A_{2}$ - and $B_{2}$-type monomers.

Polymer Journal (2013) 45, 909-914; doi:10.1038/pj.2013.11; published online 20 February 2013

Keywords: AB-type monomer; nucleophilic aromatic substitution reaction; poly(ether sulfone); self-polycondensation

\section{INTRODUCTION}

Aromatic poly(ether sulfone)s (PESs) are well-known engineering plastics that exhibit excellent thermal, mechanical and chemical stability. ${ }^{1,2}$ Owing to their amorphous nature, PESs are usually soluble in organic solvents in contrast to semicrystalline poly(ether ketone)s. The solubility of PESs enables the preparation of coatings and thin films via a solvent-casting method for advanced technologies. ${ }^{3}$ In general, PESs are synthesized via a nucleophilic aromatic substitution $\left(\mathrm{S}_{\mathrm{N}} \mathrm{Ar}\right)$ reaction between dihalogenated diphenylsulfones $\left(A_{2}\right)$ and bisphenols $\left(B_{2}\right)$ in the presence of a weak base such as potassium carbonate. ${ }^{4,5}$ Many types of PES have been reported in literatures by changing the monomer combination. ${ }^{6,7}$ However, the polycondensation between $\mathrm{A}_{2^{-}}$and $\mathrm{B}_{2}$-type monomers requires a strict equimolar ratio of functionalities in order to achieve a high-molecular-weight polymer. Furthermore, the functional groups located at the terminal are not controlled in the polycondensation of $\mathrm{A}_{2}$ - and $\mathrm{B}_{2}$-type monomers. Therefore, it is difficult to prepare $\mathrm{AB}$ - and $\mathrm{ABC}$-type block copolymers.

Self-polycondensation of AB-type monomers is an advantageous route to produce high-molecular-weight polymers without considerable adjustment of the mole ratio of the monomers. ${ }^{8,9}$ This method also allows the formation of polymers incorporating two different functionalities at the chain ends. ${ }^{10}$ Therefore, two different reactions can be performed at each end, enabling the preparation of $A B-$ and ABC-type block copolymers. ${ }^{11-14}$

In this study, we report the synthesis of PESs via the selfpolycondensation of four different AB-type monomers. The reactivity of the AB-type monomers was systematically investigated using model reactions and nuclear magnetic resonance (NMR) measurements in order to discuss an appropriate structure for the self-polycondensation. The self-polycondensation was performed via a $S_{N} A r$ reaction between phenoxides and phenyl halides using potassium carbonate as a base. High-molecular-weight polymers were obtained via selfpolycondensation of novel $\mathrm{AB}$-type monomers (monomers $\mathrm{C}$ and $\mathrm{D}$ ).

\section{EXPERIMENTAL PROCEDURE}

\section{Materials}

4,4'-Dichlorodiphenyl sulfone and 4-benzyloxyphenol were purchased from Sigma-Aldrich (St Louis, MO, USA) and used as received. 4,4'-Difluorodiphenyl sulfone, palladium on activated carbon (Pd 10\%), N,N-dimethylacetamide (DMAc), dimethyl sulfoxide (DMSO) and toluene were purchased from Wako Pure Chemical Industries Ltd (Osaka, Japan) and used without purification. 4-Chlorophenyl phenyl sulfone and 4-phenoxyphenol were purchased from Tokyo Kasei Kogyo Co. Ltd (Tokyo, Japan) and used as received.

Synthesis of 4-chloro-4'-hydroxydiphenyl sulfone (monomer A) To a solution of $4,4^{\prime}$-dichlorodiphenyl sulfone $(2.30 \mathrm{~g}, 8.0 \mathrm{mmol})$ in DMSO $(15 \mathrm{ml})$ was added potassium hydroxide $(1.12 \mathrm{~g}, 20 \mathrm{mmol})$ and the mixture was stirred at $80^{\circ} \mathrm{C}$ for $50 \mathrm{~h} .{ }^{15}$ After the reaction, the solution was poured into water and acidified by $1 \mathrm{~N}$ HClaq. The precipitate was corrected by filtration and purified by column chromatography on silica gel (chloroform/ ethyl acetate $=1 / 1, \mathrm{v} / \mathrm{v})$. The yield was $1.55 \mathrm{~g}(72 \%) .{ }^{1} \mathrm{H}$ NMR $\left(\right.$ DMSO- $d_{6}$, $\delta$, p.p.m.): 7.01 (d, 2H), 7.68 (d, 2H), 7.85 (d, 2H), 7.95 (d, 2H), 10.79 
(s, 1H). ${ }^{13} \mathrm{C}$ NMR (DMSO- $d_{6}$, $\delta$, p.p.m.): $116.8,129.3,130.2,130.6,130.8$, $138.7,141.7,162.9$

\section{Synthesis of 4-fluoro-4'-hydroxydiphenyl sulfone (monomer B)}

4-Fluoro-4'-hydroxydiphenyl sulfone was prepared from 4,4'-difluorodiphenyl sulfone $(2.03 \mathrm{~g}, 8.0 \mathrm{mmol})$ as a raw compound in the same manner as described above. ${ }^{15}$ Owing to the high reactivity of $4,4^{\prime}$-difluorodiphenyl sulfone, the mixture was stirred at $80^{\circ} \mathrm{C}$ for $10 \mathrm{~min}$. The yield was $1.32 \mathrm{~g}$ (66\%). ${ }^{1} \mathrm{H}$ NMR (DMSO- $d_{6}, \delta$, p.p.m.): $7.00(\mathrm{~d}, 2 \mathrm{H}), 7.46(\mathrm{t}, 2 \mathrm{H}), 7.85$ (d, $2 \mathrm{H}), 8.00-8.03(\mathrm{~m}, 2 \mathrm{H}), 10.75$ (s, $1 \mathrm{H}) .{ }^{13} \mathrm{C}$ NMR (DMSO- $d_{6}, \delta$, p.p.m.): 116.7, $117.2,117.4,130.5,130.5,130.6,131.2,139.2,139.2,162.8,164.0,166.1$.

\section{Synthesis of 4-chloro-4'-(4-hydroxyphenyloxy)diphenyl sulfone (monomer C)}

To a two-neck flask equipped with a nitrogen inlet were added $4,4^{\prime}$ dichlorodiphenyl sulfone $(0.57 \mathrm{~g}, 2.0 \mathrm{mmol})$, 4-benzyloxyphenol $(0.32 \mathrm{~g}$, $1.6 \mathrm{mmol})$, potassium carbonate $(0.24 \mathrm{~g}, 1.8 \mathrm{mmol})$ and DMAc $(4 \mathrm{ml})$. The reaction mixture was stirred at $120^{\circ} \mathrm{C}$ for $24 \mathrm{~h}$ under nitrogen, and then DMAc was removed by vacuum distillation. The resulting solid was dissolved in chloroform and filtered to remove inorganic salts. The filtrate was concentrated and dried under vacuum. The crude product was used for the next step without further purification.

To a solution of the crude product in methanol $(10 \mathrm{ml})$ and tetrahydrofuran $(10 \mathrm{ml})$ was added $\mathrm{Pd}$ on activated carbon $(0.08 \mathrm{~g})$, and the mixture was vigorously stirred under hydrogen atmosphere. After stirring for $36 \mathrm{~h}$, the reaction mixture was filtered through celite to remove Pd on activated carbon. The filtrate was concentrated and the residue was purified by column chromatography on silica gel (chloroform/ethyl acetate $=2 / 1, \mathrm{v} / \mathrm{v}$ ). The yield was $0.51 \mathrm{~g}(89 \%)$. M.p.: $127^{\circ} \mathrm{C} .{ }^{1} \mathrm{H}$ NMR (DMSO- $d_{6}, \delta$, p.p.m.): $6.87(\mathrm{~d}, 2 \mathrm{H})$, $6.99(\mathrm{~d}, 2 \mathrm{H}), 7.06(\mathrm{~d}, 2 \mathrm{H}), 7.69(\mathrm{~d}, 2 \mathrm{H}), 7.95-7.98(\mathrm{~m}, 4 \mathrm{H}), 9.61(\mathrm{~s}, 1 \mathrm{H}) .{ }^{13} \mathrm{C}$ NMR (DMSO- $d_{6}, \delta$, p.p.m.): 117.1, 117.3, 122.4, 129.6, 130.3, 130.6, 133.9, 139.1, 141.0, 146.4, 155.45, 163.5. Anal. Calcd for $\left(\mathrm{C}_{18} \mathrm{H}_{13} \mathrm{ClO}_{4} \mathrm{~S}\right)$ : $\mathrm{C}, 59.92 ; \mathrm{H}$, 3.63; Found: C, 59.98; H, 3.56

\section{Synthesis of 4-fluoro-4'-(4-hydroxyphenyloxy)diphenyl sulfone (monomer D)}

To a two-neck flask equipped with a nitrogen inlet were added 4,4' difluorodiphenyl sulfone $(5.09 \mathrm{~g}, 20 \mathrm{mmol})$, 4-benzyloxyphenol $(3.20 \mathrm{~g}$, $16 \mathrm{mmol})$, potassium carbonate $(2.43 \mathrm{~g}, 18 \mathrm{mmol})$ and DMAc $(40 \mathrm{ml})$. The reaction mixture was stirred at $40^{\circ} \mathrm{C}$ for $72 \mathrm{~h}$ under nitrogen, and then DMAc was removed by vacuum distillation. The resulting solid was dissolved in chloroform and filtered to remove inorganic salts. The filtrate was concentrated and dried under vacuum. The crude product was used for the next step with no further purification.

To a solution of the crude product in methanol $(100 \mathrm{ml})$ and tetrahydrofuran $(100 \mathrm{ml})$ was added $\mathrm{Pd}$ on activated carbon $(0.8 \mathrm{~g})$, and the mixture was vigorously stirred under hydrogen atmosphere. After stirring for $36 \mathrm{~h}$, the reaction mixture was filtered through celite to remove Pd on activated carbon. The filtrate was concentrated and the residue was purified by column chromatography on silica gel (chloroform/ethyl acetate $=2 / 1, \mathrm{v} / \mathrm{v}$ ). The yield was $4.10 \mathrm{~g}(74 \%)$. M.p.: $169^{\circ} \mathrm{C} .{ }^{1} \mathrm{H}$ NMR (DMSO- $d_{6}, \delta$, p.p.m.): 6.87 (d, $2 \mathrm{H}$ ), $6.99(\mathrm{~d}, 2 \mathrm{H}), 7.05(\mathrm{~d}, 2 \mathrm{H}), 7.47(\mathrm{t}, 2 \mathrm{H}), 7.96(\mathrm{~d}, 2 \mathrm{H}), 8.03-8.06(\mathrm{~m}, 2 \mathrm{H}), 9.60$ $(\mathrm{s}, 1 \mathrm{H}) .{ }^{13} \mathrm{C}$ NMR (DMSO- $d_{6}, \delta$, p.p.m.): 117.1, 117.3, 117.4, 117.5, 122.4, 130.5, 130.8, 130.9, 134.2, 138.5, 138.6, 146.4, 155.4, 163.4, 164.2, 166.2. Anal. Calcd for $\left(\mathrm{C}_{18} \mathrm{H}_{13} \mathrm{FO}_{4} \mathrm{~S}\right)$ : C, 62.78; H, 3.81; Found: C, 62.96; H, 3.77.

\section{Synthesis of 4-(phenylsulfonyl)phenol}

To a solution of 4-chlorophenyl phenyl sulfone $(2.02 \mathrm{~g}, 8.0 \mathrm{mmol})$ in DMSO $(15 \mathrm{ml})$ was added potassium hydroxide $(1.12 \mathrm{~g}, 20 \mathrm{mmol})$ and the mixture was stirred at $80^{\circ} \mathrm{C}$ for $50 \mathrm{~h}$. After the reaction, the solution was poured into water and acidified by $1 \mathrm{~N}$ HClaq. The precipitate was corrected by filtration and purified by column chromatography on silica gel (chloroform/ethyl acetate $=1 / 1, \mathrm{v} / \mathrm{v})$. The yield was $1.59 \mathrm{~g}(85 \%) .{ }^{1} \mathrm{H}$ NMR $\left(\right.$ DMSO- $d_{6}, \delta$, p.p.m.): 6.95 (d, 2H), 7.60 (t, 2H), 7.65 (t, 1H), 7.79 (d, 2H), 7.90 (d, 2H),
10.66 (s, 1H). ${ }^{13} \mathrm{C}$ NMR (DMSO- $d_{6}, \delta$, p.p.m.): 116.6, 127.3, 130.1, 130.4, $131.2,133.6,142.8,162.6$.

\section{Model reaction}

To a two-neck flask equipped with a nitrogen inlet were added 4-phenoxyphenol (0.28 g, $1.5 \mathrm{mmol})$, 4-chlorophenyl phenyl sulfone $(0.38 \mathrm{~g}, 1.5 \mathrm{mmol})$, potassium carbonate $(0.26 \mathrm{~g}, 1.9 \mathrm{mmol})$ and DMAc $(3 \mathrm{ml})$. The reaction mixture was stirred at $120^{\circ} \mathrm{C}$ under nitrogen and sampled at different time. The ${ }^{1} \mathrm{H}$ NMR spectra of the sampled fractions in DMSO- $d_{6}$ were measured to determine the conversions. The model reaction used 4-(phenylsulfonyl)phenol instead of 4-phenoxyphenol was also performed in the same manner as described above.

\section{Self-polycondensation of AB-type monomers}

The experimental procedure for the self-polycondensation of 4-chloro-4'-(4hydroxyphenyloxy)diphenyl sulfone is described as follows. To a roundbottomed flask equipped with a Dean-Stark trap, 4-chloro-4'-(4-hydroxyphenyloxy)diphenyl sulfone $(0.54 \mathrm{~g}, 1.5 \mathrm{mmol})$ and $\mathrm{K}_{2} \mathrm{CO}_{3}(0.26 \mathrm{~g}, 1.9 \mathrm{mmol})$ were charged. Then, DMAc $(3 \mathrm{ml})$ and toluene $(3 \mathrm{ml})$ were added into the flask and the reaction mixture was stirred at $150^{\circ} \mathrm{C}$ for $2 \mathrm{~h}$. After removal of toluene, the reaction temperature was increased to $160^{\circ} \mathrm{C}$ and the reaction was continued for $24 \mathrm{~h}$. After cooling to room temperature, the mixture was poured into water. The resulting fiber was filtered and washed with water. The polymer was dried in vacuo at $120^{\circ} \mathrm{C}$ for $12 \mathrm{~h}$. The yield was $0.45 \mathrm{~g}(92 \%)$.

\section{Measurements}

The ${ }^{1} \mathrm{H}$ and ${ }^{13} \mathrm{C}$ NMR spectra were recorded using a JEOL JNM-ECX 500 NMR spectrometer (JEOL, Tokyo, Japan). The gel permeation chromatography measurements (three Shodex LF-804 columns) with a refractive index detector (Wyatt Optilab Rex, Santa Barbara, CA, USA) were carried out by using $\mathrm{N}$-methylpyrrolidinone as a solvent at a flow rate of $0.5 \mathrm{ml} \mathrm{min}{ }^{-1}$. Number- and weight-average molecular weights were calibrated by standard polystyrene samples. Thermogravimetric measurements were carried out by a Rigaku Thermo plus TG 8230 (Rigaku, Tokyo, Japan) at a heating rate of $10{ }^{\circ} \mathrm{C} \mathrm{min}^{-1}$. Differential scanning calorimetric measurements were carried out with a Rigaku Thermo plus DSC 8230. The heating and cooling rates were set to be $10^{\circ} \mathrm{C} \mathrm{min}^{-1}$.

\section{RESULTS AND DISCUSSIONS}

\section{Monomer synthesis}

AB-type monomers without ether linkage (monomers A and B) were prepared by hydrolysis of dihalogenated diphenylsulfones using potassium hydroxide, as described in the literature (Scheme 1). ${ }^{15}$ Compared with the dichloro as a starting material, the difluoro system required a relatively short reaction time $(10 \mathrm{~min})$. The considerable difference in reactivity is derived from the stability of the Meisenheimer intermediates; namely, 4,4'-difluorodiphenylsulfone with small and highly electronegative fluorine atoms is readily attacked by nucleophiles. ${ }^{216}$ The structures of monomers A and B were confirmed by ${ }^{1} \mathrm{H}$ and ${ }^{13} \mathrm{C}$ NMR spectroscopy.

The two monomers incorporating an ether linkage (monomers $\mathrm{C}$ and D) were initially synthesized via a $S_{N} A r$ reaction between dihalogenated diphenylsulfones and 4-benzyloxyphenol, followed by debenzylation using a palladium-on-activated-carbon catalyst (Scheme 2). A higher reaction temperature in the first step was

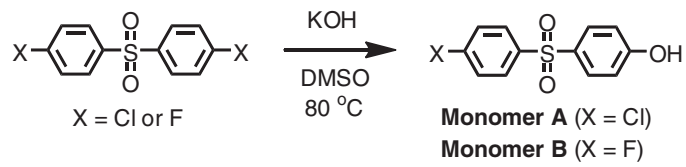

Scheme 1 Synthesis of monomers A and B. 
required for 4,4'-dichlorodiphenyl sulfone because of the poor stability of the Meisenheimer intermediates compared with the difluoro case. The crude products from the first step containing a small amount of the di-substituted products were used without further purification in the second deprotection reactions because the di-substituted products were easily removed by column chromatography after the second reactions. The structures of monomers $\mathrm{C}$ and $\mathrm{D}$ were determined by ${ }^{1} \mathrm{H}$ and ${ }^{13} \mathrm{C}$ NMR spectroscopy and elemental analysis.

\section{Model reactions}

In order to evaluate the reactivity of the monomers, model reactions using 4-chlorophenyl phenyl sulfone and phenol derivatives were conducted (Scheme 3). In the model reactions, 4-phenoxyphenol and 4-(phenylsulfonyl)phenol were investigated in order to estimate the reactivity of the hydroxyl groups in monomers $\mathrm{A}$ and $\mathrm{C}$. The conversions of the model reactions were determined by ${ }^{1} \mathrm{H}$ NMR spectroscopy of the sampling fractions, and the spectra of the aromatic region are shown in Figure 1. As for the model reaction between 4-phenoxyphenol and 4-chlorophenyl phenyl sulfone, new signals, derived from the para-position of the phenoxy group of the resulting model compound, were observed at 7.35 p.p.m. In the model reaction using 4-(phenylsulfonyl)phenol, new signals at 7.09 p.p.m. were assigned to the ortho-position of the ether linkage of the resulting model compound. The conversions of the model reactions were calculated from the integral ratios between the signals from starting materials and new signals from the resulting model compound. Figure 2 shows the relationship between the conversion and the reaction time. Clearly, the coupling reaction rapidly proceeded in the case of 4-phenoxyphenol compared with 4-(phenylsulfonyl)phenol. This result clearly indicates that the nucleophilicity of 4-phenoxyphenol is greater than that of 4-(phenylsulfonyl)phenol. In general, the acidity of a nucleophile affects the nucleophilicity; phenols with lower acidity exhibit higher nucleophilicity. ${ }^{17}$ In this model reaction, the less-acidic 4-phenoxyphenol showed higher reactivity as expected.

The reactivity of the monomers toward nucleophiles is strongly influenced by the halogen type, as observed in the monomer syntheses. In addition, the reactivity of the halogens is affected by the monomer structures. As the chemical shifts of NMR signals are

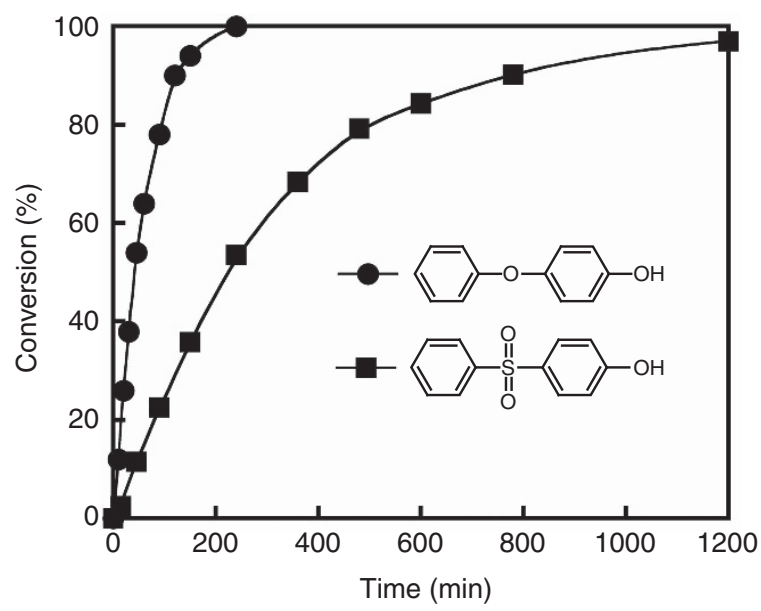

Figure 2 Relationship between conversion and the reaction time in model reactions.
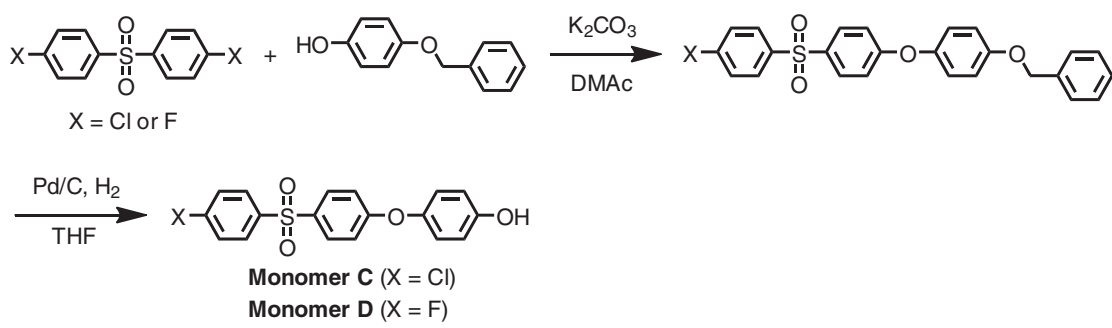

Scheme 2 Synthesis of monomers C and D.

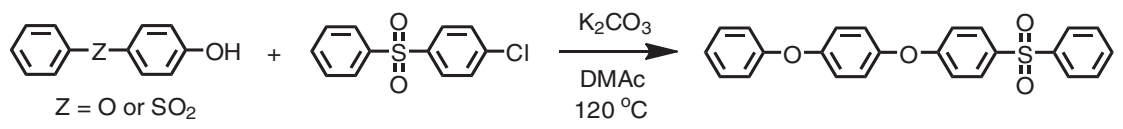

Scheme 3 Model reactions for nucleophilic aromatic substitution $\left(S_{N} A r\right)$ with different phenols.
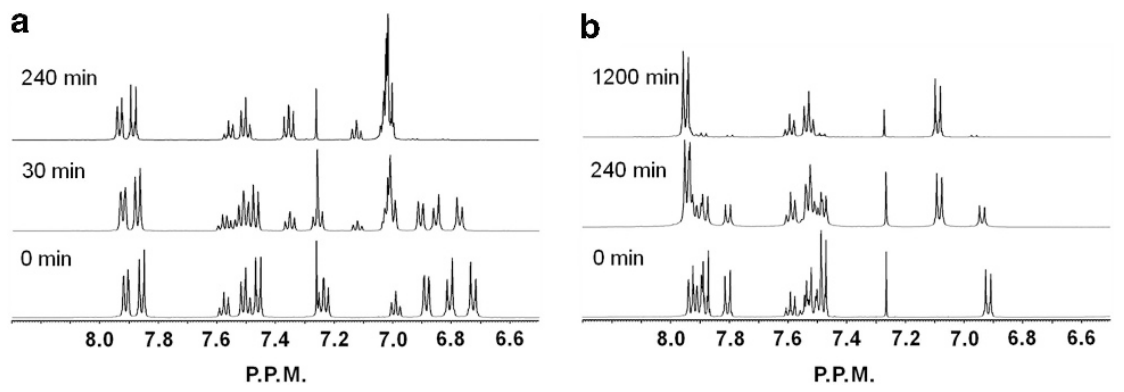

Figure $1^{1} \mathrm{H}$ nuclear magnetic resonance (NMR) spectra of sampling fractions of model reactions using (a) 4-phenoxyphenol and (b) 4(phenylsulfonyl)phenol. 
very sensitive to the electron density, NMR measurements would be a useful tool for evaluating monomer reactivity. ${ }^{18}$ Therefore, monomer reactivity toward nucleophiles was evaluated using NMR spectroscopy. To simulate the polymerization reaction, potassium salts of the monomers were prepared using potassium hydroxide. Figure 3 shows the ${ }^{13} \mathrm{C}$ NMR spectra of the monomers and their potassium-salt forms. For monomers A and B, the peaks corresponding to the carbon atoms attached to the halogens exhibit clear upfield shifts after the salt formation. It is clear that the electron density on the halogen-attached carbons of the potassium salts A and B increases because of the strong electron-donating effect of the phenolate anions. Therefore, monomers A and B are presumably deactivated by the salt formation. On the other hand, for monomers $\mathrm{C}$ and $\mathrm{D}$, the peaks assigned to the carbon atoms connected to the halogens present no upfield shift, even after the salt formation. This result clearly indicates that the electron-donating effects of the phenolate anions are negligible for the potassium salts of monomers $\mathrm{C}$ and $\mathrm{D}$. Thus, the reactivity of monomers $\mathrm{C}$ and $\mathrm{D}$ is expected to be unchanged after
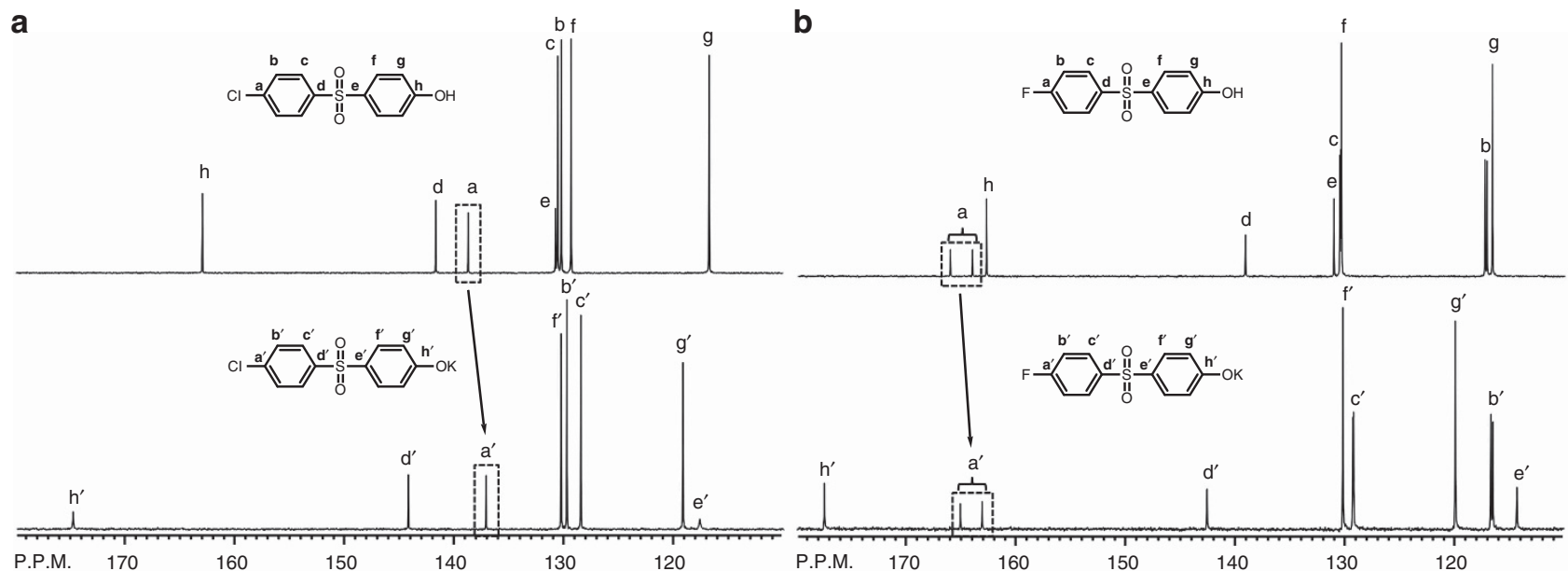

C
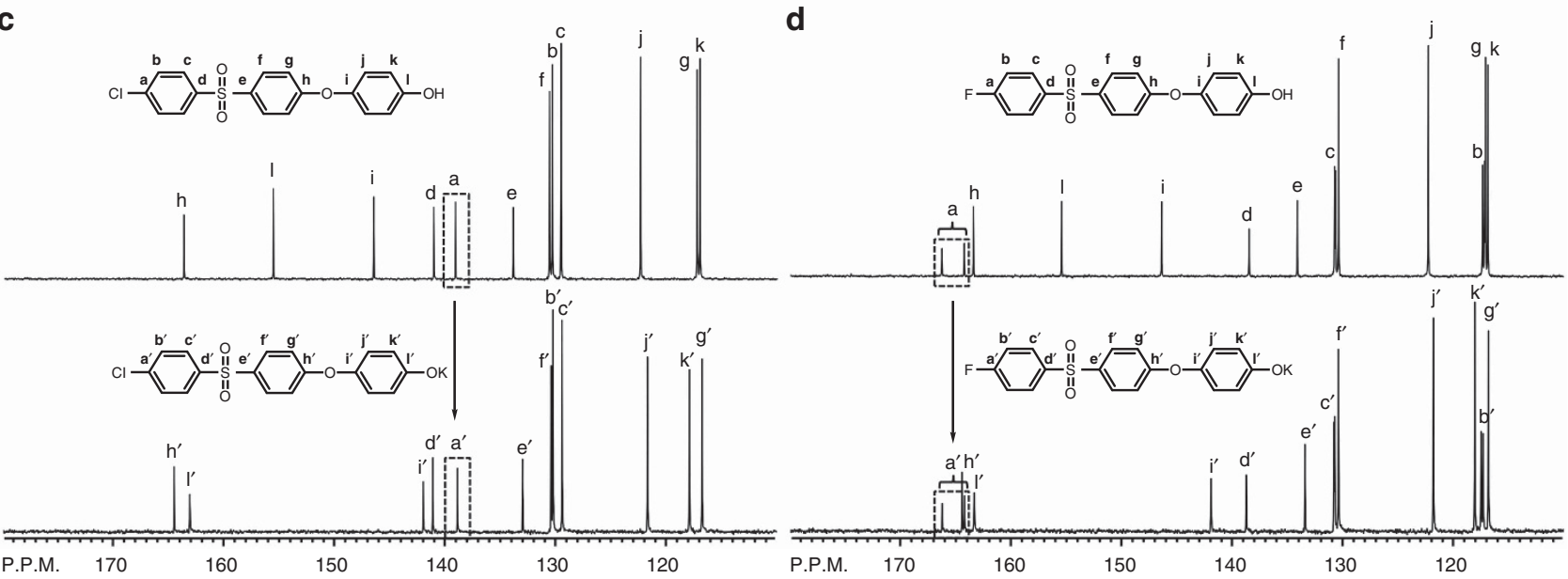

Figure $3{ }^{13} \mathrm{C}$ nuclear magnetic resonance (NMR) spectra of monomers and their potassium salt forms. (a) Monomer $\mathrm{A}$, (b) monomer $\mathrm{B}$, (c) monomer $\mathrm{C}$ and (d) monomer D.

a
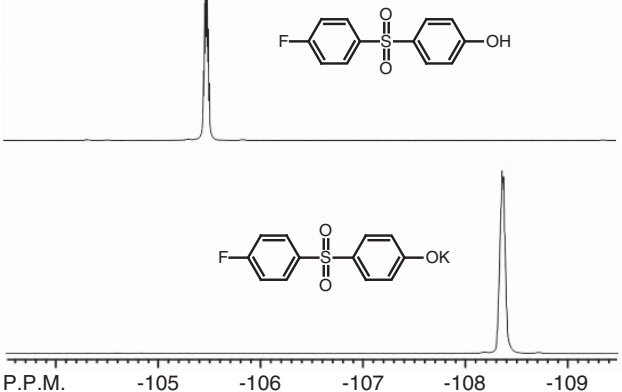

b
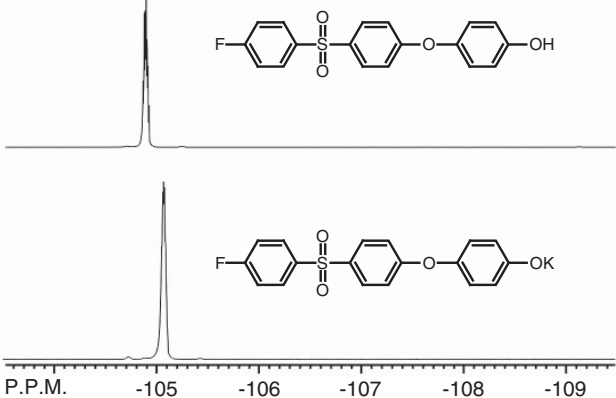

Figure $4{ }^{19} \mathrm{~F}$ nuclear magnetic resonance (NMR) spectra of monomers and their potassium salt forms. (a) Monomer B and (b) monomer D. 

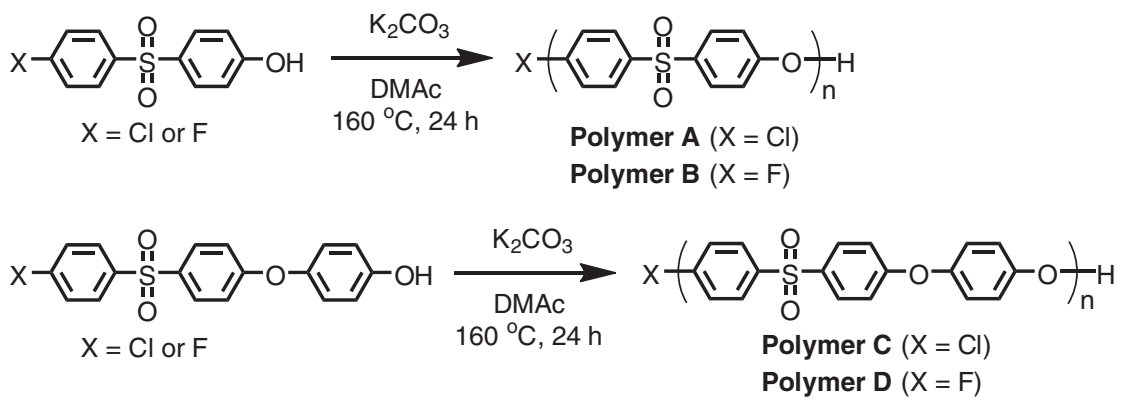

Scheme 4 Self-polymerization of AB-type monomers.

Table 1 Polymerization results of AB-type monomers

\begin{tabular}{lcrc}
\hline Monomer & Yield (\%) & \multicolumn{1}{c}{ Mwa } & $M w / M n^{\mathrm{a}}$ \\
\hline Monomer A & 71 & 8000 & 1.3 \\
Monomer B & 93 & 60000 & 1.3 \\
Monomer C & 92 & 113000 & 1.7 \\
Monomer D & 95 & 111000 & 1.7 \\
\hline
\end{tabular}

aDetermined by gel permeation chromatography (GPC) based on polystyrene standards.

Table 2 Thermal properties of polymers

\begin{tabular}{lcc}
\hline Sample & $T_{d 5}\left({ }^{\circ} \mathrm{C}\right)$ & $T_{g}\left({ }^{(} \mathrm{C}\right)$ \\
\hline Polymer B & 440 & 222 \\
Polymer D & 494 & 207 \\
\hline
\end{tabular}

salt formation. We also studied the monomer reactivity by ${ }^{19} \mathrm{~F}$ NMR measurements. Carter reported that ${ }^{19} \mathrm{~F}$ NMR chemical shifts of aryl fluoride monomers can be used to evaluate their reactivity toward nucleophilic substitution reactions. ${ }^{18}$ The ${ }^{19} \mathrm{~F}$ NMR spectra of the fluorinated monomers and their salt forms are shown in Figure 4. The salt formation of the monomers caused upfield shifts of the ${ }^{19} \mathrm{~F}$ signals, implying reduction in reactivity. In the case of monomer D, the chemical shift was slightly changed from -104.9 to -105.1 p.p.m. after salt formation. The small change in the chemical shift suggests that the reactivity of monomer $\mathrm{D}$ is insensitive to salt formation. On the other hand, the salt formation of monomer $\mathrm{B}$ induced a large change in the chemical shift from -105.5 to -108.4 p.p.m. The large shift implies that the reactivity of monomer B clearly decreases after the salt formation. These ${ }^{19} \mathrm{~F}$ NMR results are consistent with ${ }^{13} \mathrm{C}$ NMR measurements; namely, reactivity of monomer B toward nucleophiles notably decreases by salt formation in contrast to monomer D.

\section{Polymerization}

The self-polycondensation of the monomers A-D was performed in the presence of potassium carbonate at $160^{\circ} \mathrm{C}$ for $24 \mathrm{~h}$ to yield the polymers A-D (Scheme 4). The polymerization results are summarized in Table 1 . The lowest molecular-weight polymer $\left(M_{\mathrm{w}}=8000\right)$ was obtained from monomer A. Monomer B yielded highermolecular-weight polymer than monomer A, although both monomers gave the same polymer structure. It is known that the $S_{N} A r$ reactivity of $\mathrm{F}$ is greater than that for $\mathrm{Cl}$ because of the stability of the
Meisenheimer intermediates. Therefore, the reactivity of monomer A is not sufficient to produce a high-molecular-weight polymer. The high-molecular-weight polymers $\left(M_{\mathrm{w}}\right.$ over $\left.110000 \mathrm{Da}\right)$ were obtained in the case of monomers $\mathrm{C}$ and $\mathrm{D}$. This result is as expected since the monomers should possess both high nucleophilicity and high reactivity toward nucleophiles according to the model reactions. No significant difference in the molecular weights between polymers $\mathrm{C}$ and D was found, whereas monomer D clearly yielded a highermolecular-weight polymer than monomer B. This indicates that the spacer group in monomer D strongly affects the polymerization, as anticipated by the model reactions. It is noteworthy that neither the polymers A nor B could be synthesized by a $S_{N} A r$ reaction between $A_{2}$ and $\mathrm{B}_{2}$ monomers. Moreover, the polymers prepared in this study have two different functional groups (hydroxyl and halogen) at the chain ends, which can be used as building blocks for AB- or ABC-type block copolymers.

\section{Thermal properties}

Thermal stability is one of the most important properties of PESs. The decomposition temperatures and glass transition temperatures $\left(T_{\mathrm{g}} \mathrm{s}\right)$ were measured by thermogravimetry and differential scanning calorimetry, respectively. The results are summarized in Table 2. Polymers B and D showed high 5 wt $\%$ weight loss temperatures. Polymer $\mathrm{B}$ exhibited higher $T_{\mathrm{g}}$ than polymer $\mathrm{D}$, indicating that the former polymer has a more rigid structure than the latter because of the presence of only one ether linkage in the repeating unit. The resulting $T_{\mathrm{g}}$ values in this study are consistent with reported values. $^{19,20}$

\section{CONCLUSIONS}

Four different AB-type monomers including two novel species were prepared to form PESs. The reactivity of the AB-type monomers was systematically investigated using model reactions and NMR measurements. In the model reactions, the less acidic 4-phenoxyphenol showed higher $\mathrm{S}_{\mathrm{N}} \mathrm{Ar}$ reactivity than 4-(phenylsulfonyl)phenol. NMR measurements suggest that the spacer groups in monomers $C$ and D effectively weakened the strong electron-donating effect caused by formation of the phenoxide anions. The self-polycondensation of the $\mathrm{AB}$ monomers was indeed influenced by the reactivity of the monomers. The high-molecular-weight polymers were obtained from monomers $\mathrm{C}$ and D. The resulting PESs exhibited high-thermal properties comparable to the PESs prepared from $A_{2}$ and $B_{2}$ monomers. Since the polymers prepared in this study have two different functional groups at chain ends, unique $\mathrm{AB}$ - and $\mathrm{ABC}$-type block copolymers can be prepared using the different terminal functions. 
1 Dumais, J. J., Cholli, A. L., Jelinski, L. W., Hedrick, J. L. \& McGrath, J. E. Molecular basis of the $\beta$-transition in poly(arylene ether sulfones). Macromolecules 19, 1884-1889 (1986).

2 Rogers, M. E. \& Long, T. E. (eds) Synthetic Methods in Step-Growth Polymers (John Wiley and Sons, Inc., Hoboken, NJ, USA, 2003).

3 Nady, N., Franssen, M. C. R., Zuilhof, H., Eldin, M. S. M., Boom, R. \& Schroën, K. Modification methods for poly(arylsulfone) membranes: a mini-review focusing on surface modification. Desalination 275, 1-9 (2011).

4 Viswanathan, R., Johnson, B. C. \& McGrath, J. E. Synthesis, kinetic observations and characteristics of polyarylene ether sulphones prepared via a potassium carbonate DMAc process. Polymer 25, 1827-1836 (1984).

5 Ueda, M., Toyota, H., Ouchi, T., Sugiyama, J., Yonetake, B., Masuko, T. \& Teramoto, T. Synthesis and characterization of aromatic poly(ether sulfone)s containing pendant sodium sulfonate groups. J. Polym. Sci., Part A: Polym. Chem 31, 853-858 (1993).

6 Kricheldorf, H. R. \& Bier, G. New polymer synthesis. IX. Synthesis of poly(ether sulfone)s from silylated diphenols or hydroxybenzoic acids. J. Polym. Sci., Polym. Sci. Ed 21, 2283-2289 (1983).

7 Matsumoto, K., Higashihara, T. \& Ueda, M. Locally and densely sulfonated poly(ether sulfone)s as proton exchange membrane. Macromolecules 42, 1161-1166 (2009).

8 Attwood, T. E., Barr, D. A., Feasey, G. G., Leslie, V. J., Newton, A. B. \& Rose, J. B. Poly(arylene ether sulphones) by polyetherification: 1 . Synthesis of halogenophenols. Polymer 18, 354-358 (1977).

9 Attwood, T. E., Barr, D. A., King, T., Newton, A. B. \& Rose, J. B. Poly(arylene ether sulphones) by polyetherification: 2. Polycondensations. Polymer 18, 359-364 (1977).

10 Percec, V., Rinaldi, P. L. \& Auman, B. C. Comb-like polymers and graft copolymers from monomers. Polym. Bull. 10, 215-222 (1983).
11 Yokozawa, T. \& Yokoyama, A. Chain-growth polycondensation: living polymerization nature in polycondensation and approach to condensation polymer architecture. Polym. J 36, 65-83 (2004).

12 Yokozawa, T. \& Yokoyama, A. Chain-growth polycondensation: the living polymerization process in polycondensation. Prog. Polym. Sci. 32, 147-172 (2007).

13 Park, J., Moon, M., Seo, M., Choi, H. \& Kim, S. Y. Well-defined star-shaped rod-coil diblock copolymers as a new class of unimolecular micelles: encapsulation of guests and thermoresponsive phase transition. Macromolecules 43, 8304-8313 (2010).

14 Matsumoto, K., Higashihara, T. \& Ueda, M. Star-shaped sulfonated block copoly(ether ketone)s as proton exchange membranes. Macromolecules 41, 7560-7565 (2008).

15 Newton, A. B. \& Rose, J. B. Relative reactivities of the functional groups involved in synthesis of poly(phenylene ether sulphones) from halogenated derivatives of diphenyl sulphone. Polymer 13, 465-474 (1972).

16 Mani, R. S., Zimmerman, B., Bhatnagar, A. \& Mohanty, D. K. Poly(aryl ether ketone) synthesis via competing $\mathrm{S}_{N} A R$ and $\mathrm{S}_{\mathrm{RN}} 1$ reactions: 1 . Polymers derived from 1,3-bis $(p$ chlorobenzoyl)benzene and 1,3-bis( $p$-fluorobenzoyl)benzene with hydroquinone and 4,4'-isopropylidenediphenol. Polymer 34, 171-181 (1993).

17 Jaramillo, P., Pérez, P. \& Fuentealba, P. Relationship between basicity and nucleophilicity. J. Phys. Org. Chem 20, 1050-1057 (2007).

18 Cater, K. R. Aryl fluoride monomers in nucleophilic aromatic substitution polymerization: evaluation of monomer reactivity by ${ }^{19} \mathrm{~F}$ NMR spectroscopy. Macromolecules $\mathbf{2 8}$, 6462-6470 (1995).

19 Matsuoka, S. Thermodynamic theory of viscoelasticity. J. Therm. Anal 46, 985-1010 (1996).

20 Oishi, Y., Nakata, S., Kakimoto, M. \& Imai, Y. Synthesis and properties of segmented aromatic poly(ether sulfone)-amide and poly(ether sulfone)-imide copolymers. J. Polym. Sci., Part A: Polym. Chem 30, 2217-2221 (1992). 